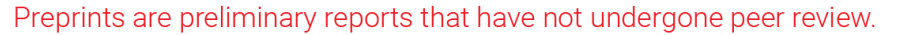 \\ They should not be considered conclusive, used to inform clinical practice, or referenced by the media as validated information. \\ Spatial and epidemiological analysis of Covid-19 in Ardabil province,North West of Iran
}

\section{Shahram Habibzadeh}

Ardabil University of Medical Sciences

Abbas Abbasi Ghahramanloo

Ardabil University of Medical Sciences

\section{Said Sadeghieh Ahari}

Ardabil University of medical science

Eslam Moradi-Asl ( $\nabla$ moradiasl83@yahoo.com )

Ardabil University of Medical Sciences

Shabnam Asghari

Ardabil University of Medical Sciences

\section{Research Article}

Keywords: COVID-19, Spatial Analysis, Epidemiology, Ardabil, Iran

Posted Date: December 20th, 2021

DOl: https://doi.org/10.21203/rs.3.rs-919352/v1

License: (c) (1) This work is licensed under a Creative Commons Attribution 4.0 International License. Read Full License 


\section{Abstract}

Background: Coronavirus disease highly contagious, is prevalent in all age and sex groups infecting the respiratory system. The aim of this study are spatial analysis and geographical distribution of Covid-19 in different time periods in Ardabil province.

Methods: In this cross-sectional study, official statistics recorded in the health centers of Counties and hospitals of Ardabil province were used from 20/03/2020 to 20/03/2021. For data analysis was used to Chi-square to investigate the relationship between disease peaks. In order to perform spatial analysis, were used to ArcGIS10.4.8 software and IDW interpolation analysis and Moran index was used to determine the pattern of disease spread in the study area.

Results: The duration of the three peaks in Ardabil province was about 10 months and 11,761 people were referred to hospitals. The longest peak was the third peak, which lasted 72 days. Bilehsavar County with the highest incidence of 1334 and Kowsar County with 226/100000 has the lowest incidence of the disease. Covid-19 distribution pattern based on Moran's index shows that the incidence of disease in high-risk areas in all three peaks was significantly clustered $(P<0.05)$

Conclusions: Covid-19 process during the three peaks in Ardabil province has been increasing in terms of incidence and duration of the peak. Take action in all Counties and to implement health protocols.

\section{Introduction}

On December 31, 2019, reports of many cases of pneumonia of unknown cause in Wuhan, China raised concerns about an epidemic in the region, which increased with the spread of fears of its spread and spread throughout the world (1).The disease, originally named New Coronavirus-2501, was eventually designated as Acute Respiratory Acute Syndrome (SARS-CoV-2) by the International Committee for the Classification of Viruses (2).Symptoms of Covid-11's disease reported by the World Health Organization include fever, dry cough, shortness of breath, extreme tiredness, and lymphopenia; In more severe cases, viral pneumonia infections can lead to acute respiratory syndrome and even death $(3,4)$.One of the most important ways to control and prevent mortality from this disease is vaccination. Several types of vaccines such as killed and inactivated vaccines, live attenuated viruses, subunit vaccines, recombinant proteins and DNA vaccines for coronaviruses are produced and produced in the world and are in use (5, 6).Geographical epidemiology is a part of descriptive epidemiology that studies the geographical distribution, severity of morbidity and mortality, and one of the most important applications of geographical epidemiology is to obtain clues to determine the causes of diseases, injuries or deaths (7).The first step in analyzing geographic data is to visualize it, especially in the form of geographical maps, which clearly show the pattern of geographical distribution of diseases, injuries, and deaths, and pave the way for the development of etiological hypotheses. Because statistical tables do not have this capability compared to maps, the use of GIS and maps in health and medical sciences has increased significantly in recent years (10-8).Spatial modeling capacity in Geographic Information System(GIS)is 
directly used to understand the differences in the spatial distribution of diseases and their relationship to environmental factors and the health care system, so that GIS technology is currently a major tool in health research and management, and of this system It is used in health research in the field of infectious diseases (11).In this study, the incidence of Covid-19 disease in northwestern Iran during one year in terms of spatial analysis and geographical distribution in different time periods has been studied and its epidemiological variables have been analyzed.

\section{Materials And Methods}

Study area: this study was conducted in Ardabil province north west of Iran with geographic coordinates of northern 38.4853 and eastern 47.8911 . The province has a total area of $17953 \mathrm{sq} \mathrm{km}$ (about $1.09 \%$ of the country's total area)and 1338 meters above sea level, and its population is estimated at one million and 249 , according to the 2015 census. The province is bordered to the north by the Republic of Azerbaijan to the east by Gilan and to the west to East Azerbaijan Province and to the south to Zanjan Province.

Data collection: In this cross-sectional study, official statistics recorded in the health centers of Counties and hospitals of Ardabil province were used from 20/03/2020 to 20/03/2021. The characteristics of all patients who were treated with experimental detection based on positive and positive PCR were extracted based on age, gender, residence and study.

Data analysis: One-way analysis of variance was used to compare the mean age of patients in the first, second and third peaks. Chi-square was also used to investigate the relationship between disease peaks and gender, disease outcome, PCR outcome, hospitalization status and ICU hospitalization. logistic regression analyzes were used to investigate the effect of different variables on mortality due to Covid-19 and crude odds ratio estimation and multiple logistic regression was used to adapt the odds ratio estimate.

Spatial analysis:In order to perform spatial analysis, the information was entered into the spatial database in ArcGIS10.4.8 software and the distribution maps of disease cases in different years were drawn in ArcMap. IDW interpolation analysis was used to determine high-risk areas in terms of disease in the province $(P<0.05)$. Moran index was used to determine the pattern of disease spread in the study area.

\section{Results}

Epidemiological analysis aspects: The duration of the three peaks in Ardabil province was about 10 months and 11,761 people were referred to hospitals. The longest peak was the third peak, which lasted 72 days. Also, in the third peak, there was the highest number of hospital visits (Table 1).Table 2 shows the relationship between demographic variables and indicators related to Covid-19 in terms of peaks in Ardabil province. This table shows that the mean age of patients in the first, second and third peaks is 
increasing. This table also shows that in the first and second peaks, men are slightly more infected than women, but in the third peak, women are more infected.

In general, of the total number of patients referred to the hospital, about $8 \%$ died in the first peak, about $12 \%$ in the second peak and $11 \%$ in the third peak. Table 2 shows that there is a statistically significant relationship between all variables and disease peaks. Table 3 shows the effect of variables affecting the death of Covid-19. This table shows that after adjustment for other variables, age, hospitalization, ICU admission, and positive PCR result significantly increase the chance of death. It should be noted that in terms of gender, this effect was significant only in the third peak. This table shows that hospitalization in the first peak has the strongest association with death from Covid-19 $(O R=18.74)$. After hospitalization, ICU hospitalization in the first peak had the strongest association with death $(\mathrm{OR}=6.61)$. The weakest correlation is related to the effect of age, which slightly increased the chance of death in all three peaks.

Results of spatial analysis: The results of spatial analysis of the disease during the three peaks of the study showed that the incidence of the disease in the four counties of Bilehsavar, Ardabil, Parsabad and Meshginshahr had the highest incidence of disease, respectively. Bilehsavar County with the highest incidence of 1334 per hundred thousand people and Kowsar County with 226 per hundred thousand people has the lowest incidence of the disease (Fig.1).

The results of separate peaks showed that the first peak of Ardabil County was one of the high-risk areas and the incidence of the disease was between 140-120 per hundred thousand people.In the second peak, five Counties of Ardabil, Meshginshahr, Nir, Bilehsavar and Namin with an incidence of 225-120 per hundred thousand cases were among the important centers of the disease, the peak intensity had doubled at the peak and in the third peak more than 70 Percentage of Ardabil province was severely infected with Covid-19 and seven Counties of Ardabil, Meshginshahr, Parsabad, Bilehsavar, Garmi, Nir and Sarein with an incidence of 120-34 per hundred thousand people were among the most dangerous centers of the disease (Fig.2). The disease distribution pattern based on Moran's index shows that the incidence of disease in high-risk areas in all three peaks was significantly clustered $(P<0.05)(F i g .3)$.

\section{Discussion}

In the first and second peaks, the incidence was higher in women than men, but in the third peak, this trend has changed and the incidence has increased in men. The average death rate during the epidemic was $10.43 \%$, the highest of which occurred in the second peak (12.2\%). Considering that the second peak occurred in the summer and many trips were made to Ardabil province at that time and Also, the possibility of people normalizing that the disease decreases in summer with increasing temperature and the rate of observance of health protocols decreases, is one of the important factors influencing this peak.

The results of this study show that the age group of 20-55 years is the highest percentage of patients with coronavirus, which shows that the active population of the country has been the most infected with coronavirus in the last three peaks. And Mir in this age group will face Ardabil province with a population 
crisis and then the economic crisis of the productive strata of society. Studies on the epidemiological characteristics of coronavirus in Iran so far also show that the proportion of men with coronavirus is higher than women and most cases are in the age range of 60-50 years (12).

In the first peak, the rate of ICU hospitalization and Positive PCR test was high, which could be due to the emergence of the disease and people's lack of familiarity with the disease, thus increasing the chance of mortality. Other countries, the first courier is more severe and deadly and has caused a lot of casualties $(13,14)$. One of the important characteristics of the emergence of the disease is that human knowledge about the dimensions of the disease becomes long-term control and prevention (15).

Also, the cluster pattern obtained from the distribution of coronavirus in Ardabil province shows that the disease is concentrated in some Counties and its spread to surrounding Counties.One of the most important factors in the spatial dispersion of Corona in the province is the centralization of population distribution in the centers of densely populated Counties such as Ardabil, Meshginshahr and Parsabad. Due to the concentration of the population and the development of service and medical departments and other departments in Ardabil, which is the capital of the province, and the increase in population density in this part of the province has led to the same factor in the corona virus has caused the spread of the disease.

In a study conducted in Hubei Province, China, the results of Moran coefficient spatial patterns showed that spatial clusters with an increasing trend and sudden change, due to the intense concentration of population, caused the outbreak of Coronavirus in this province, which confirms the results of our study $(16,17)$.The number of Counties where Covid-19 disease has spread has shown a significant increase in subsequent peaks, and the incidence of the disease in Counties has increased. In most parts of the world, with the change of virus strains and the increase in the spread of the disease, more new places have been infected and the spread of the disease has spread. Lack of control over land and air travel is one of the main reasons for dispersion in different parts of the world $(18,19)$.

\section{Conclusion}

Considering that the pattern of disease distribution in Ardabil province has been clustered and also the disease process during the three peaks has been increasing in terms of incidence and duration of the peak, it is recommended in the next peaks to quickly identify disease clusters. Take action in different Counties and take serious action to implement health protocols.

\section{Declarations}

\section{Acknowledgements}

The authors thank Ardabil Health Central and all hospitals staff for enabling this study.

\section{Funding}


This research was supported by a grant from Ardabil University of Medical Sciences (project No: 1003742).

\section{Ethics approval and consent to participate}

The study was approved by the Ethics Committee of Ardabil University of Medical Sciences (IR.ARUMS.REC.1399.142). Permission to conduct the study was obtained from this committee and all patients had signed an informed consent form.

\section{Consent for publication}

Not applicable.

\section{Competing interests}

The authors declare no conflict of interest.

\section{References}

1. Xu Z, Shi L, Wang Y, Zhang J, Huang L, Zhang C, et al. Pathological findings of COVID-19 associated with acute respiratory distress syndrome. The Lancet respiratory medicine. 2020;8(4):420-2.

2. Farnoosh G, Alishiri G, Hosseini Zijoud SR, Dorostkar R, Jalali Farahani A. Understanding the severe acute respiratory syndrome coronavirus 2 (SARS-CoV-2) and coronavirus disease (COVID-19) based on available evidence-a narrative review. J Mil Med. 2020;22(1):1-11.

3. Adham D, Habibzadeh S, Ghobadi H, Jajin SA, Abbasi-Ghahramanloo A, Moradi-Asl E. Epidemiological characteristics and mortality risk factors among COVID-19 patients in Ardabil, Northwest of Iran. BMC Emergency Medicine. 2021;21(1):1-6.

4. Moradi-AsI E, Adham D, Ghobadi H, Abbasi-Ghahramanloo A. Clustering of COVID-19 Symptoms Among Iranian Patients: The Role of Preexisting Comorbidity on Latent Class Membership. Asia Pacific Journal of Public Health. 2021:10105395211017755.

5. De Wit E, van Doremalen N, Falzarano D. Munster VJJNRM. SARS and MERS: recent insights into emerging coronaviruses. 2016;14(8):523-34.

6. Ahmed SF, Quadeer AA, McKay MR. Preliminary identification of potential vaccine targets for the COVID-19 coronavirus (SARS-CoV-2) based on SARS-CoV immunological studies. Viruses. 2020;12(3):254.

7. Rezaeian M, Dunn G, St Leger S, Appleby L. Geographical epidemiology, spatial analysis and geographical information systems: a multidisciplinary glossary. Journal of Epidemiology \& Community Health. 2007;61(2):98-102. 
8. Khoshdel A, Noori Fard M, Pezeshkan R, Salahi-Moghaddam A. Mapping the important communicable diseases of Iran. Health and Development Journal. 2020;1(1):31-46.

9. Musa GJ, Chiang P-H, Sylk T, Bavley R, Keating W, Lakew B, et al. Use of GIS mapping as a public health tool--from cholera to cancer. Health services insights. 2013;6:HSI. S10471.

10. Rytkönen MJ. Not all maps are equal: GIS and spatial analysis in epidemiology. International journal of circumpolar health. 2004;63(1):9-24.

11. Tanser FC, Le Sueur D. The application of geographical information systems to important public health problems in Africa. International journal of health geographics. 2002;1(1):1-9.

12. Nikpouraghdam M, Farahani AJ, Alishiri G, Heydari S, Ebrahimnia M, Samadinia H, et al. Epidemiological characteristics of coronavirus disease 2019 (COVID-19) patients in IRAN: A single center study. Journal of Clinical Virology. 2020;127:104378.

13. Denis F, Fontanet A, Le Douarin Y-M, Le Goff F, Jeanneau S, Lescure F-X. A self-assessment webbased app to assess trends of the COVID-19 pandemic in France: Observational study. Journal of Medical Internet Research. 2021;23(3):e26182.

14. Mardani R, Vasmehjani AA, Zali F, Gholami A, Nasab SDM, Kaghazian H, et al. Laboratory parameters in detection of COVID-19 patients with positive RT-PCR; a diagnostic accuracy study. Archives of academic emergency medicine. 2020;8(1).

15. Poon LL, Peiris M. Emergence of a novel human coronavirus threatening human health. Nature medicine. 2020;26(3):317-9.

16. Yang W, Deng M, Li C, Huang J. Spatio-temporal patterns of the 2019-nCoV epidemic at the county level in Hubei Province, China. International Journal of Environmental Research and Public Health. 2020;17(7):2563.

17. Bazargan M, Amirfakhriyan M. Geographical analysis of COVID-19 epidemiology in Iran with exploratory spatial data analysis approach (ESDA). Journal Mil Med. 2020;22(6):542-52.

18. Fortaleza CMCB, Guimarães RB, Catão RdC, Ferreira CP, Berg de Almeida G, Nogueira Vilches T, et al. The use of health geography modeling to understand early dispersion of COVID-19 in São Paulo, Brazil. Plos one. 2021;16(1):e0245051.

19. Zuo YY, Uspal WE, Wei T. Airborne transmission of COVID-19: aerosol dispersion, lung deposition, and virus-receptor interactions. ACS nano. 2020;14(12):16502-24.

\section{Tables}

Table1.Details about Covid-19 peaks in Ardabil province 2020-2021 


\begin{tabular}{|c|c|c|c|c|}
\hline Peak & Start the peak & End the peak & Peak time (days) & Total hospitalization \\
\hline First & 25.March.2020 & 04.May.2020 & 40 & 2593 \\
\hline Second & 24.Jun.2020 & 28.Agu.2020 & 54 & 3532 \\
\hline Third & 28. Sep.2020 & 01.Jan.2021 & 72 & 5636 \\
\hline Total & & & 166 & 11761 \\
\hline
\end{tabular}

Table 2. Investigation of the relationship between demographic variables and indicators related to Covid-19 in terms of peaks occurred in Ardabil province 202-21

\begin{tabular}{c|c|c|c|c|}
\hline & First peak & Second peak & Third peak & P-value \\
\hline Mean age of patients & $49.67 \pm 19.83$ & $54.35 \pm 20.60$ & $54.68 \pm 20.03$ & $<0.001$ \\
\hline Gender & & & & \\
\hline Male & $1271(49.0)$ & $1695(48.0)$ & $2923(51.9)$ & 0.001 \\
\hline Female & $1322(51.0)$ & $1837(52.0)$ & $2713(48.1)$ & \\
\hline Jutcome of the disease & & & & \\
\hline Clearance & $2384(91.9)$ & $3100(87.8)$ & $5016(89.0)$ & $<0.001$ \\
\hline Death & $209(8.1)$ & $432(12.2)$ & $618(11.0)$ & \\
\hline PCR results & & & & \\
\hline Positive & $1307(51.1)$ & $2150(61.9)$ & $3412(62.5)$ & $<0.001$ \\
\hline Negative & $1250(48.9)$ & $1322(38.1)$ & $2044(37.5)$ & \\
\hline Hospitalization & & & & \\
\hline Yes & $1850(71.3)$ & $2671(75.6)$ & $4186(74.3)$ & 0.001 \\
\hline No & $743(28.7)$ & $861(24.4)$ & $1450(25.7)$ & \\
\hline ospitalization in the ICU & & & & \\
\hline Yes & $47(1.8)$ & $51(1.5)$ & $117(4.1)$ & $<0.001$ \\
\hline No & $2523(98.2)$ & $3307(98.5)$ & $2754(95.9)$ & \\
\hline
\end{tabular}

Table 3: The effect of variables affecting the death of Covid 19 in Ardabil province2020-2021 


\begin{tabular}{|l|c|c|c|c|c|c|}
\hline & \multicolumn{5}{|c|}{ Death due to COVID 19 } \\
\cline { 2 - 7 } & \multicolumn{3}{|c|}{ Crude estimation } & \multicolumn{3}{c|}{ Adjusted estimation } \\
\hline Variables & OR & 95\%CI & P & OR & 95\%CI & P \\
\hline Age & & & & & & \\
& & & & & & \\
\hline 1st peak & 1.05 & $1.04-1.06$ & $<0.001$ & 1.04 & $1.03-1.05$ & $<0.001$ \\
\hline 2nd peak & 1.04 & $1.04-1.05$ & $<0.001$ & 1.04 & $1.3-1.05$ & $<0.001$ \\
\hline 3rd peak & 1.05 & $1.04-1.06$ & $<0.001$ & 1.05 & $1.04-1.06$ & $<0.001$ \\
\hline Sex (being male) & & & & & & \\
\hline 1st peak & 1.35 & $1.02-1.80$ & 0.036 & 1.16 & $0.85-1.58$ & 0.337 \\
\hline 2nd peak & 1.04 & $0.85-1.27$ & 0.705 & 1.02 & $0.82-1.27$ & 0.880 \\
\hline 3rd peak & 1.23 & $1.04-1.46$ & 0.015 & 1.33 & $1.02-1.73$ & 0.032 \\
\hline Hospitalization & & & & & & \\
\hline 1st peak & & & & & & \\
\hline 2nd peak & 46.68 & $11.56-188.40$ & $<0.001$ & 18.74 & $4.58-76.63$ & $<0.001$ \\
\hline 3rd peak & 4.73 & $3.25-6.87$ & $<0.001$ & 3.25 & $2.18-4.86$ & $<0.001$ \\
\hline Hospitalization in ICU & 4.29 & $3.20-5.75$ & $<0.001$ & 1.99 & $1.03-3.85$ & 0.041 \\
\hline 1st peak & & & & & & \\
\hline 2nd peak & 9.42 & $5.18-17.11$ & $<0.001$ & 6.61 & $3.37-12.98$ & $<0.001$ \\
\hline 3rd peak & 5.22 & $2.96-9.21$ & $<0.001$ & 3.25 & $2.18-4.86$ & $<0.001$ \\
\hline PCR result (positive) & 2.34 & $1.47-3.69$ & $<0.001$ & 3.94 & $2.27-6.84$ & $<0.001$ \\
\hline 1st peak & & & & & & \\
\hline 2nd peak & 2.37 & $1.74-3.23$ & $<0.001$ & 1.83 & $1.31-2.55$ & $<0.001$ \\
\hline 3rd peak & 2.72 & $2.12-3.48$ & $<0.001$ & 2.41 & $1.84-3.18$ & $<0.001$ \\
\hline
\end{tabular}

\section{Figures}




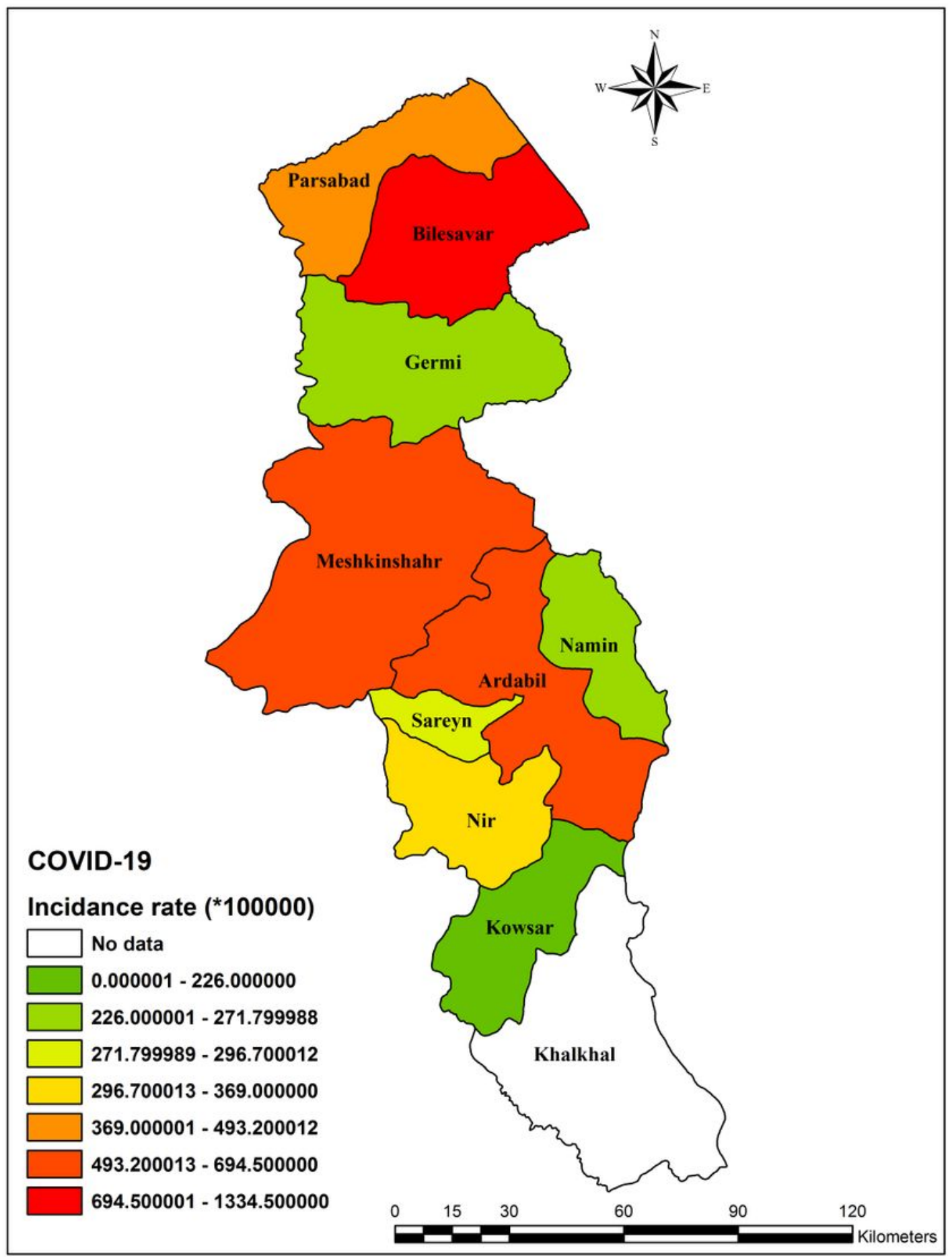

Figure 1

Figure caption not provided with this version.

Figure 2 
Figure caption not provided with this version.

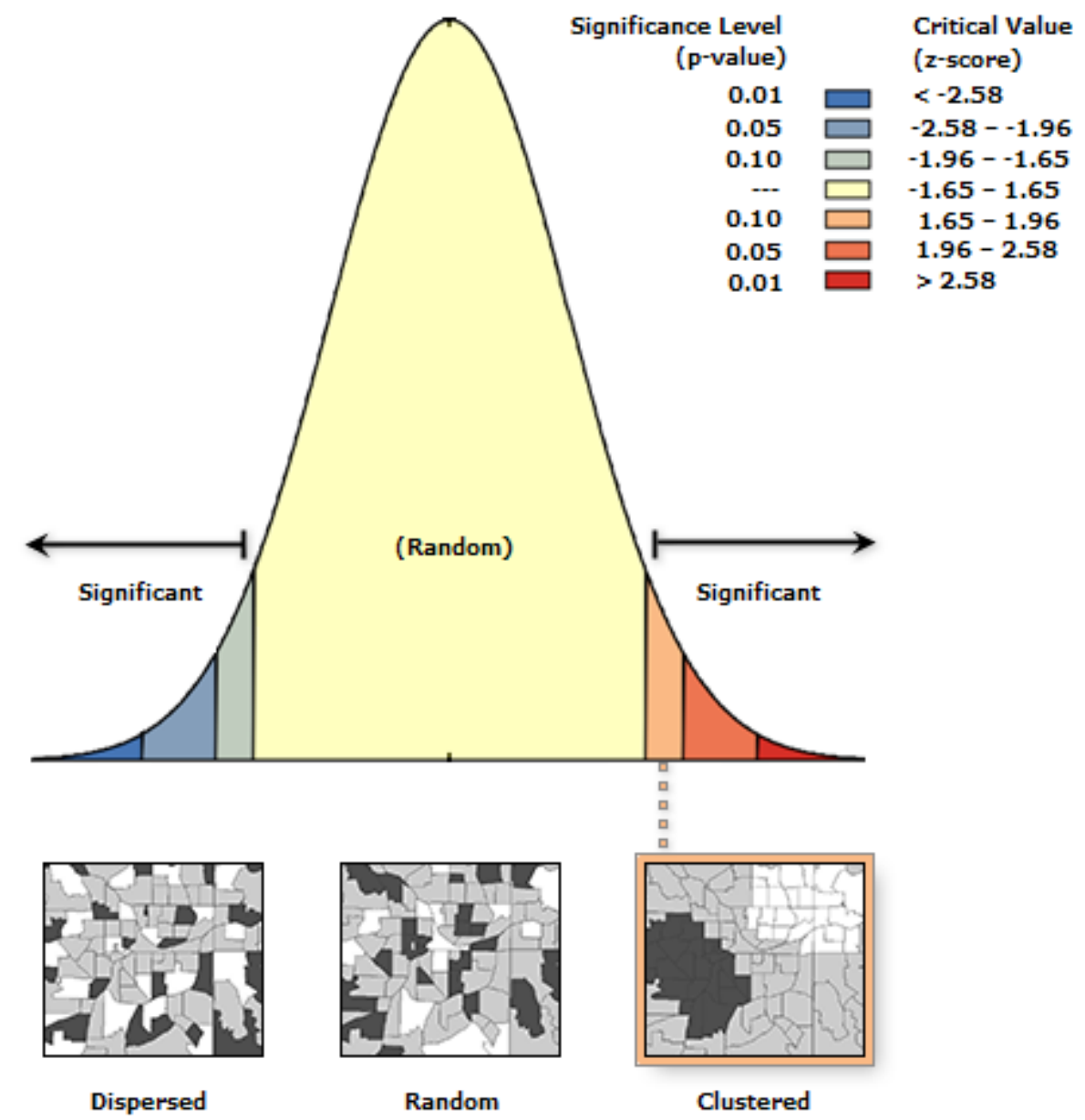

Figure 3

Figure caption not provided with this version. 